\title{
Identifying patients and clinical scenarios for use of long-acting injectable antipsychotics - expert consensus survey part I
}

This article was published in the following Dove Press journal:

Neuropsychiatric Disease and Treatment

\author{
Martha Sajatovic ${ }^{1,2}$ \\ Ruth Ross ${ }^{3}$ \\ Susan N Legacy ${ }^{4}$ \\ Christoph U Correll ${ }^{5,6}$ \\ John M Kane $\mathrm{e}^{5,6}$ \\ Faith DiBiasi ${ }^{7}$ \\ Heather Fitzgerald ${ }^{8}$ \\ Matthew Byerly9 \\ 'Department of Psychiatry, University \\ Hospitals Cleveland Medical Center, \\ Cleveland, OH, USA; ${ }^{2}$ Departments \\ of Psychiatry and Neurology, Case \\ Western Reserve University School of \\ Medicine, Cleveland, OH, USA; ${ }^{3}$ Ross \\ Editorial, Port Townsend, WA, USA; \\ ${ }^{4}$ US Medical Affairs Neuroscience, \\ Otsuka Pharmaceutical Development \& \\ Commercialization, Inc., Princeton, \\ NJ, USA; ${ }^{5}$ Psychiatry, The Zucker \\ Hillside Hospital, Glen Oaks, NY, USA; \\ ${ }^{6}$ Psychiatry, The Donald and Barbara \\ Zucker School of Medicine at Hofstra/ \\ Northwell, Glen Oaks, NY, USA; \\ ${ }^{7}$ Scientific Communications, Otsuka \\ Pharmaceutical Development \& \\ Commercialization, Inc., Rockville, \\ MD, USA; ${ }^{8}$ Medical Affairs, Lundbeck \\ LLC, Deerfield, IL, USA; ' $\mathrm{Cell}$ Biology \\ and Neuroscience, Center for Mental \\ Health Research and Recovery, \\ Montana State University, Bozeman, \\ MT, USA
}

Correspondence: Martha Sajatovic Department of Psychiatry, University Hospitals Cleveland Medical Center, 10524 Euclid Ave, Cleveland, $\mathrm{OH} 44106$, USA

Tel +I 2168442808

Fax + I 2168442742

Email martha.sajatovic@uhhospitals.org
Objective: To assess expert consensus on barriers and facilitators for long-acting injectable antipsychotic (LAI) use and provide clinical recommendations on issues where clinical evidence is lacking, including identifying appropriate clinical situations for LAI use.

Methods: A 50-question survey comprising 916 response options was distributed to 42 research experts and high prescribers with extensive LAI experience. Respondents rated options on relative appropriateness/importance using a 9-point scale. Consensus was determined using chi-square test of score distributions. Mean (standard deviation) ratings were calculated. Responses to 29 questions (577 options) relating to appropriate patients and clinical scenarios for LAI use are reported.

Results: Recommendations aligned with research on risk factors for nonadherence and poor outcomes for patients with schizophrenia/schizoaffective or bipolar disorder. Findings suggested, contrary to general practice patterns, that LAI use may be appropriate earlier in the disease course and in younger patients. Results for bipolar disorder were similar to those for schizophrenia but with less consensus. Numerous facilitators of LAI prescribing were considered important, particularly that LAIs may reduce relapses and improve outcomes.

Conclusion: Findings support wider use of LAIs in patients with schizophrenia/schizoaffective and bipolar disorders beyond the setting of poor adherence and earlier use in the disease course. Keywords: expert consensus, schizophrenia, schizoaffective disorder, bipolar disorder, long-acting injectable antipsychotics

\section{Introduction}

Long-acting injectable antipsychotics (LAIs) were first introduced for the treatment of schizophrenia more than 50 years ago, although they have remained largely underutilized despite more recent availability of second-generation LAIs (SGAs). ${ }^{1-4}$ Although their potential clinical utility is well recognized, only $15 \%-28 \%$ of eligible patients with schizophrenia in the USA receive an LAI. ${ }^{3}$ LAIs may support adherence to maintenance treatment by simplifying medication regimens. ${ }^{1,5-7}$ Although some data show comparable outcomes between oral antipsychotics and LAIs, ${ }^{8,9}$ several randomized controlled trials (RCTs) in patients with schizophrenia demonstrated a significant delay and reduction in relapse with LAIs compared with oral antipsychotics, ${ }^{10-12}$ particularly in patients with early-phase or first-episode schizophrenia. ${ }^{11,12}$ Furthermore, meta-analyses of mirror-image studies ${ }^{13}$ and cohort studies, ${ }^{14}$ which may include more real-world patients than RCTs, ${ }^{15}$ have demonstrated a lower risk of all-cause discontinuation and frequency of hospitalizations with LAIs versus oral antipsychotics. 
A recent expert consensus guideline from France recommended LAI SGAs as first-line treatment early in schizophrenia (ie, following the first psychotic episode) and for any patient when antipsychotic maintenance treatment is indicated. ${ }^{16}$ This differs from the American Psychiatric Association's (APA) Practice Guideline for the Treatment of Patients With Schizophrenia, last updated in 2004, which recommended LAIs only for recurrent relapses due to nonadherence or in patients who prefer an LAI. ${ }^{17}$ For patients with bipolar I disorder, the 2013 Canadian Network for Mood and Anxiety Treatments guidelines recommended SGA LAI risperidone as a first-line maintenance option. ${ }^{18,19}$ It is not clear how newer LAIs should be incorporated or considered in the context of existing guidelines that place LAIs as most appropriate for a relatively narrow subgroup of patients with schizophrenia/schizoaffective or bipolar disorder.

Antipsychotic nonadherence rates in schizophrenia are high; estimates as high as $>50 \%$ have been reported. ${ }^{20,21}$ Poor adherence with oral medication has been cited as a primary modifiable reason for poor outcomes ${ }^{22}$ and for prescribing LAIs. ${ }^{23,24}$ It has been shown that physicians frequently underestimate poor adherence, ${ }^{25,26}$ and this finding, combined with the belief that LAIs should be reserved for nonadherent patients, ${ }^{16}$ may contribute to the underuse of LAIs. Negative clinician attitudes and concerns about patient acceptance may also contribute to the underprescribing of LAIs. ${ }^{4,24,27-30}$

The low rate of LAI prescribing may also stem from lack of available literature on the appropriate role of these agents. Indeed, currently available clinical trial evidence is insufficient to support treatment decisions in several key areas, such as selecting appropriate patients to receive LAIs, using treatment history as an indicator for use of LAIs, determining efficacy in patients with a recent-onset versus chronic mental illness, and managing adverse effects. Identifying potential barriers that limit the use of LAIs and potential facilitators that would make a healthcare provider more likely to consider using an LAI is important for clinical decision making. The expert consensus survey methodology provides an opportunity to develop clinical recommendations where evidence is lacking or when steps to support clinical decision making cannot be feasibly identified by RCTs. ${ }^{31}$

\section{Aim of the study}

This expert consensus survey was conducted to fill gaps in literature and establish recommendations concerning appropriate use of LAIs in patients with schizophrenia/ schizoaffective or bipolar disorder.

\section{Methods}

This expert consensus survey evaluated the relative appropriateness of LAI use for a variety of patient characteristics and clinical scenarios as well as optimal prescribing practices for initiation and continuation/maintenance treatment with LAIs. The survey was administered online via SurveyMonkey ${ }^{\circledR}$ (San Mateo, CA, USA) between April and November 2016 to experts in the USA and contained 50 questions (total of 916 response options) to elicit respondents' opinions and practices regarding LAI prescribing for patients with schizophrenia/schizoaffective and bipolar disorders. Aligned with the patient assessment and clinical decision-making process, the survey was organized into 3 overarching and sequential sections: 1) identifying patients, 2) initiation of therapy, and 3) maintenance treatment (Figure S1). Responses to 29 questions, comprising 577 response options, relating to appropriate patients and clinical scenarios for use of LAIs are reported here.

Survey respondents used a 9-point scale adapted from the RAND method ${ }^{32}$ to rate predefined options, with some questions including a write-in or comments option. The rating scale ranged from 1 to 9 , with 1 representing extremely inappropriate or not important at all and 9 representing extremely appropriate or extremely important. In completing the survey, respondents were asked to draw on their personal clinical experience treating patients with schizophrenia/ schizoaffective and bipolar disorders and their knowledge of research and/or published literature. The survey took approximately 2.5-3 hours to complete and was distributed to 42 experts who were either researchers in mood and psychotic disorders with expertise in LAI trials or clinicians with extensive expertise in the use of multiple LAI formulations. Each research expert met 2 or more of the following criteria: published in the area of adherence or LAI use as it relates to patients with schizophrenia/schizoaffective disorder and/or bipolar disorder; principal investigator or co-principal investigator for studies involving LAIs for the treatment of schizophrenia and/or bipolar disorder; or individual with an advanced degree in psychology, medicine, or associated field who is responsible for the selection of treatment options for patients with schizophrenia/schizoaffective and/or bipolar disorders. Each clinician with extensive expertise fulfilled the following criteria (based on prescribing data): routinely prescribes LAIs in his or her practice; prescribes at least 2 different LAIs in his or her practice; holds an advanced degree in psychology, medicine, or associated field; and is responsible for the decision-making process for the selection of treatment options for patients 
with schizophrenia/schizoaffective and/or bipolar disorders. Respondents received an honorarium for their participation in the survey and were blinded to the study sponsor. Respondents were informed of the purpose of the survey and invited to continue by clicking a web button, which was deemed as confirming agreement. This study was exempt from approval by an institutional review board; it involved only the use of survey procedures, did not involve children, and the data was aggregated and anonymized such that none of the responses could be linked to any specific respondent.

\section{Statistical analysis}

Presence or absence of consensus on each question was defined as a distribution unlikely to occur by chance using the chi-square test $(P<0.05)$ across 3 ranges of appropriateness (1-3, 4-6, 7-9). Consistent with expert consensus survey methodology ${ }^{33}$ the mean rating with $95 \%$ confidence interval (CI) was calculated for each option in a given question. Results were summarized graphically with a horizontal box representing the $95 \% \mathrm{CI}$ for each consecutive option in a given question. Options that received a rating of 9 by $\geq 50 \%$ of respondents were marked by an asterisk and shading was used to indicate consensus. CIs of mean ratings were used to designate first-, second-, or third-line ratings (ie, items were first line if the bottom of the CI boundary was $>6.5$, second line if the bottom of the $\mathrm{CI}$ fell between 3.5 and 6.5 , and third line [not appropriate] if the bottom of the CI was $<3.5$ ). Tests of significance were not performed for most items; however, wider gaps between CIs generally indicate smaller $P$-values. Expert consensus related to identifying appropriate patients and clinical scenarios for LAI use and facilitators of and barriers to use of LAIs are summarized in this report.

\section{Results}

A total of 175 experts were invited to take the survey, 42 of whom agreed to participate (24\%). Of those sent the survey, 34 experts completed it (81\%). A list of all survey respondents and their affiliations is provided in Table S1. The demographics and experience of the expert panel are summarized in Table 1. Most respondents were psychiatrists and researchers with expertise in prescribing LAI and conducting studies using LAIs; the panel included 7 clinicians with extensive LAI prescribing expertise (high prescribers). Overall, experts had a relatively high level of clinical experience. More than half reported spending either half, a majority, or all of their time in clinical practice. In addition, they reported spending a mean of $30 \%$ of their time treating or supervising the treatment of patients with
Table I Demographics and practice characteristics of expert panel

\begin{tabular}{|c|c|}
\hline Demographic and practice experience & Value \\
\hline Mean (range) age, years & $58(42-82)$ \\
\hline Male sex, n (\%) & $21(62)$ \\
\hline Mean (range) years in practice & $25(0-45)$ \\
\hline \multicolumn{2}{|l|}{ Degree, n (\%) } \\
\hline MD & $24(7 I)$ \\
\hline $\mathrm{PhD}$ & $6(18)$ \\
\hline DNP & $2(6)$ \\
\hline PharmD & $2(6)$ \\
\hline Involved in schizophrenia, bipolar disorder, or major & $22(65)$ \\
\hline \multicolumn{2}{|l|}{ depressive disorder research (within previous 5 years), $\mathrm{n}(\%)$} \\
\hline Mean (range) research experience, years & $22(0-52)$ \\
\hline $\mathrm{NIMH/NIH} \mathrm{research} \mathrm{grant} \mathrm{as} \mathrm{principal} \mathrm{investigator,} \mathrm{n}(\%)$ & $15(44)$ \\
\hline Principal investigator for an industry-sponsored grant, $\mathrm{n}(\%)$ & $20(59)$ \\
\hline Practice environment & Value \\
\hline \multicolumn{2}{|l|}{ Proportion of time spent seeing patients, $\mathrm{n}(\%)$} \\
\hline All/majority of the time & $12(36)$ \\
\hline $50 \%$ of the time & $7(21)$ \\
\hline $25 \%$ of the time & $10(29)$ \\
\hline$<10 \%$ of the time & $5(15)$ \\
\hline \multirow{2}{*}{\multicolumn{2}{|c|}{$\begin{array}{l}\text { Practice setting(s) where significant number of patients } \\
\text { seen, }{ }^{\mathrm{a}} \mathrm{n}(\%)\end{array}$}} \\
\hline & \\
\hline Private practice & $8(25)$ \\
\hline Public sector & II (34) \\
\hline Academic clinical or research setting & $23(69)$ \\
\hline \multirow{2}{*}{\multicolumn{2}{|c|}{$\begin{array}{l}\text { Mean percentage of time (range) spent treating or } \\
\text { supervising the treatment of patients, by disease }\end{array}$}} \\
\hline & \\
\hline Schizophrenia/schizoaffective disorder & $30(0-100)$ \\
\hline Bipolar disorder & $25(0-75)$ \\
\hline Major depressive disorder & $24(0-60)$ \\
\hline \multirow{2}{*}{\multicolumn{2}{|c|}{$\begin{array}{l}\text { Mean percentage of patients (range) with insurance } \\
\text { coverage }\end{array}$}} \\
\hline & \\
\hline Private insurance & $30(0-100)$ \\
\hline Medicaid & $33(0-75)$ \\
\hline Medicare & $22(0-70)$ \\
\hline Uninsured & $15(0-70)$ \\
\hline \multicolumn{2}{|l|}{ Mean percentage of patients (range) treated by age group } \\
\hline$<18$ years & $10(0-75)$ \\
\hline I8-34 years & $35(0-55)$ \\
\hline $35-65$ years & $41(0-70)$ \\
\hline$>65$ years & $13(0-65)$ \\
\hline \multicolumn{2}{|l|}{$\begin{array}{l}\text { Mean percentage of patients (range) in practice currently } \\
\text { receiving LAl, by disease }\end{array}$} \\
\hline Schizophrenia/schizoaffective disorder & $33(0-100)$ \\
\hline Bipolar disorder & II $(0-40)$ \\
\hline
\end{tabular}

Note: aSome experts may have provided $>$ I response.

Abbreviations: LAl, long-acting injectable antipsychotic; $\mathrm{NIMH} / \mathrm{NIH}$, National Institute of Mental Health/National Institutes of Health.

schizophrenia/schizoaffective disorder and $25 \%$ of their time treating or supervising the treatment of patients with bipolar disorder. The first survey question asked how confident these experts were in assessing their patients' adherence to oral medication, and most indicated they were only somewhat confident $(45 \%)$ or not very confident $(33 \%)$. 


\section{Selecting appropriate patients}

Experts rated the appropriateness of initiating an LAI in patients with schizophrenia/schizoaffective or bipolar disorder based on a variety of demographic and clinical characteristics. Options that received a ranking of 9 by $>50 \%$ on experts were considered extremely appropriate. Options rated first line were considered very or usually appropriate, second line as somewhat appropriate, and third line as inappropriate. For a patient with schizophrenia/schizoaffective disorder who has been treated with an antipsychotic medication for $\geq 2$ years, regardless of whether the person is considered generally adherent or not; the experts gave firstline rankings (very or usually appropriate) to considering an LAI in the following clinical situations: poor insight into illness and need for treatment, homeless or unstable housing situation, history of multiple $(>2)$ hospitalizations for psychotic relapses, history of violence to others, living alone, history of a suicide attempt, substance use disorder, prominent psychotic symptoms, young adult (age 18-25 years), and cognitive impairment. As can be seen in Figure 1, recommendations for a patient with bipolar disorder who has been treated with medication for $\geq 2$ years and is considered generally adherent to treatment were generally the same as for schizophrenia but with only 2 items receiving first-line consensus: history of multiple hospitalizations and homeless or unstable housing situation. If the adherence of the longerterm patient with bipolar disorder is questionable, the experts also gave first-line ratings to a history of violence and poor insight.

Results were similar when experts were asked about patients with schizophrenia/schizoaffective or bipolar disorder of recent onset. For a patient with schizophrenia/ schizoaffective disorder with onset during the previous 2 years, a history of multiple $(>2)$ hospitalizations for psychotic relapses, homeless or unstable housing situation, and history of violence to others were rated by $\geq 50 \%$ of experts as extremely appropriate (rating $=9$ ) factors for LAI use. Poor insight into illness and need for treatment,

\title{
Survey questions:
}

\begin{abstract}
Question 2. Consider the scenario of a patient with an established diagnosis of schizophrenia or schizoaffective disorder who
\end{abstract} has been treated with antipsychotic medication for $\geq 2$ years whom you assume is generally adherent to treatment.

Question 5. Consider the scenario of a patient with an established diagnosis of bipolar disorder who has been treated with medication to manage the bipolar disorder for $\geq 2$ years whom you assume is generally adherent to treatment.

How appropriate would you consider it to initiate treatment with an LAl in this patient given the presence of each of the following demographic or clinical characteristics?

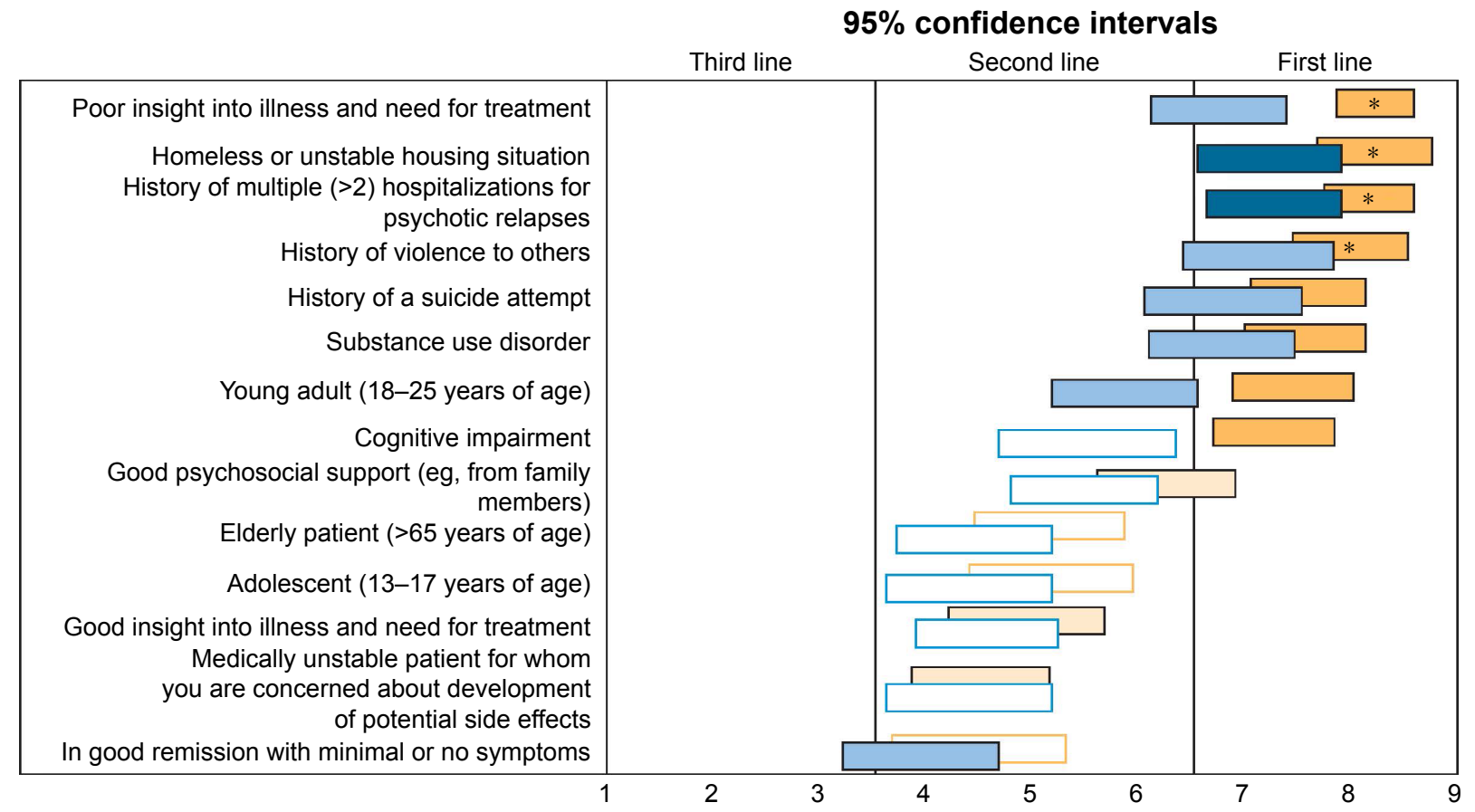

Figure I Expert consensus on selecting appropriate patients with schizophrenia/schizoaffective and bipolar disorders for LAI treatment.

Notes: Rating scale: I = extremely inappropriate, 2-3= usually inappropriate, 4-6= sometimes appropriate, 7-8=usually appropriate, 9= extremely appropriate. Horizontal bars represent Cls. $*$ Options that received highest ranking by $\geq 50 \%$ of respondents. Open bars indicate no consensus; shaded bars indicate consensus (dark shading $=$ first line; medium shading = second line; light shading = third line). Colors of the survey questions correlate to the colors in the figure.

Abbreviation: LAI, long-acting injectable antipsychotic. 
living alone, prominent psychotic symptoms, and history of suicide attempt also received first-line ratings.

Recommendations for LAI use in a patient with bipolar disorder of recent onset ( $<2$ years) were similar to those for schizophrenia/schizoaffective disorder, but only homeless or unstable housing situation, history of violence to others, and history of multiple $(>2)$ hospitalizations for bipolar relapses received consensus ratings as usually appropriate.

When considering treatment history, factors considered by consensus to be extremely appropriate for LAI use in schizophrenia/schizoaffective disorder were similar regardless of adherence status (Table 2). Experts agreed that patients who have a preference for LAIs, have done well on an LAI in the past, or have family conflict related to oral medication nonadherence are all extremely appropriate candidates for LAI treatment. In patients with questionable adherence, frequently missing clinic appointments was an additional scenario in which LAI use was considered to be extremely appropriate (Table 2).

When considering treatment history in patients with bipolar disorder who were treated with medication for $\geq 2$ years, consensus was reached on 2 situations as extremely appropriate for LAI use (Table 3). Similar to schizophrenia/ schizoaffective disorder, $\geq 50 \%$ of experts agreed that LAIs are extremely appropriate for patients with bipolar disorder who prefer an LAI, regardless of treatment adherence. In addition, experts agreed it is extremely appropriate (rated 9 by $\geq 50 \%$ of the experts) to use an LAI for a patient

Table 2 Expert consensus on selecting patients with schizophrenia/schizoaffective disorder who are appropriate for LAI treatment based on treatment history

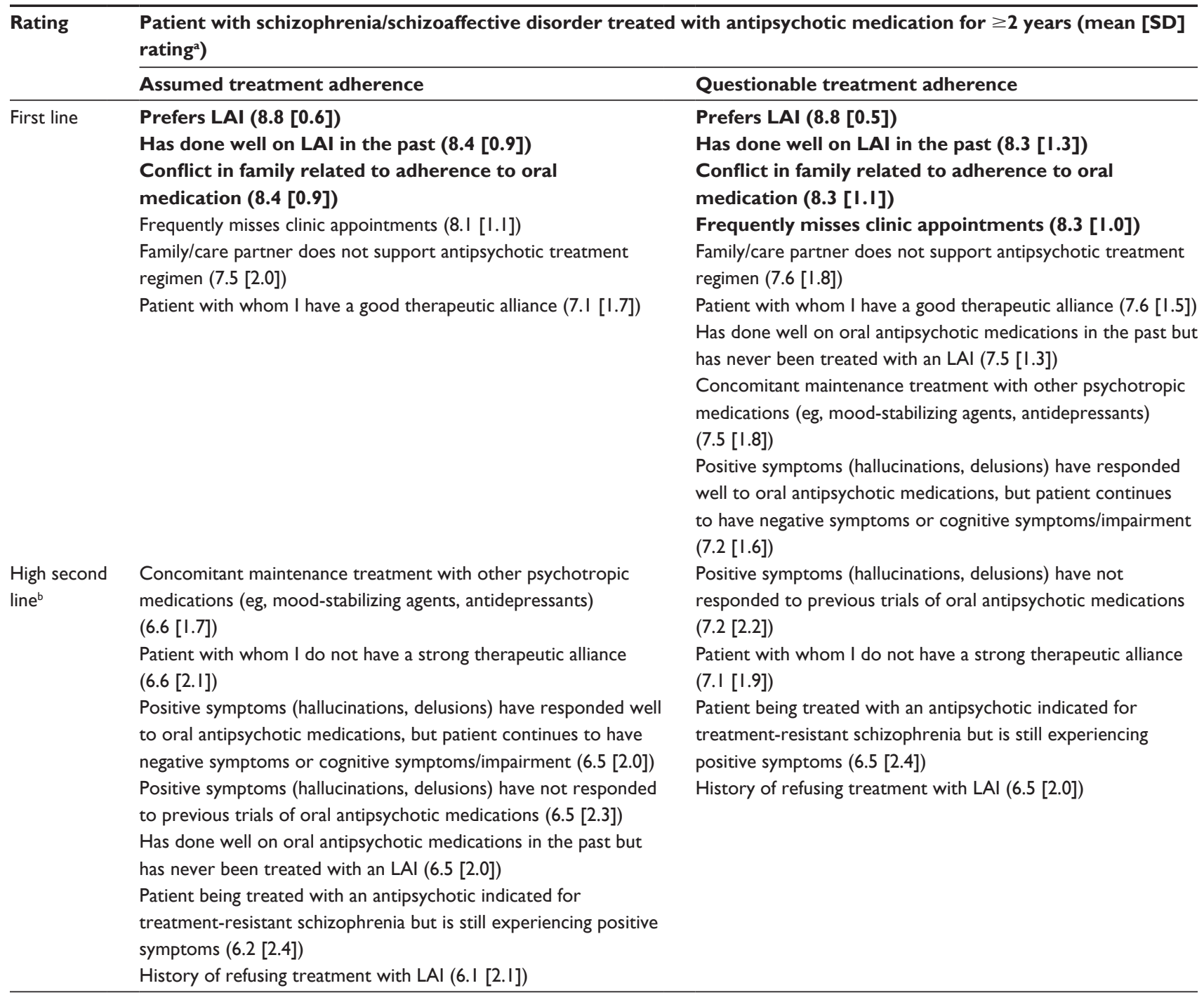

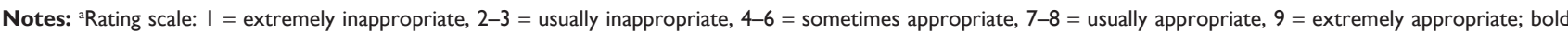
indicates an option rated 9 by $\geq 50 \%$ of the experts. bHigh second-line options are those for which the upper value of the $\mathrm{Cl}$ is $\geq 6.5$, the boundary for first line. Abbreviation: LAl, long-acting injectable antipsychotic. 
Table 3 Expert consensus on selecting patients with bipolar disorder who are appropriate for LAl treatment based on treatment history

\begin{tabular}{|c|c|c|}
\hline \multirow[t]{2}{*}{ Rating } & \multicolumn{2}{|c|}{$\begin{array}{l}\text { Patient with established diagnosis of bipolar disorder and treated with medication for } \geq 2 \text { years (mean [SD] } \\
\text { rating }^{\text {) }}\end{array}$} \\
\hline & Assumed treatment adherence & Questionable treatment adherence \\
\hline \multirow[t]{8}{*}{ First line } & Prefers LAI (8.4 [0.9]) & Prefers LAI (8.6 [0.7]) \\
\hline & History of suboptimal adherence to medications (7.6 [1.2]) & Has done well on LAl in the past $(8.3[\mathrm{I} .0])$ \\
\hline & Has done well on LAI in the past (7.5 [1.5]) & History of suboptimal adherence to medications (7.9 [1.3]) \\
\hline & Frequently misses clinic appointments (7.3 [1.7]) & Frequently misses clinic appointments (7.4 [I.5]) \\
\hline & & Has failed to respond to lithium or anticonvulsant \\
\hline & & mood-stabilizing medications (7.I [ 1.8$])$ \\
\hline & & Predominant history of manic relapse $(7.1[1.8])$ \\
\hline & & Patient with whom I have a good therapeutic alliance (7.I [ I.8]) \\
\hline \multirow{9}{*}{$\begin{array}{l}\text { High second } \\
\text { line }^{b}\end{array}$} & Has shown only partial response to lithium or & Has shown only partial response to lithium or anticonvulsant \\
\hline & anticonvulsant mood-stabilizing medications (6.9 [1.5]) & mood-stabilizing medications (7.0 [1.7]) \\
\hline & Has failed to respond to lithium or anticonvulsant & Patient with whom I do not have a strong therapeutic alliance \\
\hline & Patient with whom I have a good therapeutic alliance & Concomitant treatment with other mood-stabilizing agents or \\
\hline & $\begin{array}{l}\text { (6.8 [1.9]) } \\
\text { Patient with whom I do not have a strong therapeutic }\end{array}$ & anticepressants ( $0.1[2.0]$ ) \\
\hline & alliance $(6.6[1.8])$ & has never been treated with an LAl (6.6 [2.0]) \\
\hline & Predominant history of manic relapse (6.5 [I.7]) & \\
\hline & Has done well on oral antipsychotic medications in the & \\
\hline & past but has never been treated with an LAI (6.0 [2.3]) & \\
\hline
\end{tabular}

Notes: ${ }^{a}$ Rating scale: I = extremely inappropriate, $2-3=$ usually inappropriate, 4-6 = sometimes appropriate, 7-8 = usually appropriate, $9=$ extremely appropriate; bold indicates an option rated 9 by $\geq 50 \%$ of the experts. bHigh second-line options are those for which the upper value of the $\mathrm{Cl}$ is $\geq 6.5$, the boundary for first line.

Abbreviation: LAI, long-acting injectable antipsychotic.

with bipolar disorder when adherence is questionable and an LAI has worked well in the past (Table 3). Other factors considered usually appropriate for LAI use in patients with bipolar disorder treated with medication for $\geq 2$ years who are assumed to be generally adherent to treatment were those with a history of suboptimal adherence to medications, having previously done well on an LAI, and frequently missing clinic appointments. In those with questionable adherence, experts agreed that LAIs are usually appropriate when adherence to medications has been suboptimal in the past, clinic appointments are frequently missed, prior lithium or anticonvulsant mood stabilizer treatment has failed, relapses are predominantly manic, or when the therapeutic alliance is good.

\section{Facilitators of and barriers to prescribing long-acting injectable antipsychotics}

Experts were also asked to rank the importance of potential barriers to healthcare providers prescribing LAIs. Barriers were divided into 3 different categories: patient related, system related, or medication related. Although none of the barriers received first-line ratings (indicating that none were viewed as barriers that consistently stood out as being most important), a number of barriers did receive high second-line ratings. For potential patient-related barriers, high secondline consensus ratings were given for a patient who does not want an injection and/or is afraid of needles, perceives LAIs as coercive or punitive, and whose family does not support use of LAIs. When asked about potential system-related barriers, LAIs not being adequately covered by insurance plans, inability to bill for injection and office visit on the same day, and LAI being too costly were all factors that received high second-line consensus ratings. Finally, medicationrelated barriers receiving high second-line consensus ratings were the patient having had a previous bad experience with an LAI and the existence of treatment guidelines that suggest reserving LAIs for patients with multiple relapses, nonadherence, or previous LAI experience. Lack of clarity concerning the appropriate LAI dosage received a consensus second-line rating.

In addition to ranking potential LAI barriers, respondents were also asked to write in what they considered to be the top 3 barriers limiting use of LAIs. The most important barriers were all potentially modifiable factors and included drug cost, insurance reimbursement, negative patient perceptions of LAIs, stigma associated with injections, lack of knowledge of or experience with LAIs, and limited staff/infrastructure (Table S2).

After rating potential barriers to LAI use, the experts ranked the relative importance of a list of factors, beliefs, and perceptions as potential facilitators to LAI prescribing in patients with schizophrenia, schizoaffective disorder, 
Table 4 First- and high second-line expert ratings on the importance of potential facilitators for consideration of LAl use in a patient with schizophrenia/schizoaffective or bipolar disorder

\begin{tabular}{|c|c|}
\hline Rating & $\begin{array}{l}\text { Factors, beliefs, or perceptions about LAls by healthcare providers that would facilitate } \\
\text { consideration of an LAI (mean [SD] rating }{ }^{\mathrm{a}} \text { ) }\end{array}$ \\
\hline First line & $\begin{array}{l}\text { Reduced risk of relapse and hospitalization }(8.3[1.0]) \\
\text { Improved patient outcomes }(\mathbf{8 . 2}[\mathbf{I} . \mathrm{I}]) \\
\text { No need for patient to make a daily decision to take medication or remember to take medication daily (8.I [0.9]) } \\
\text { Reduced symptoms because of continuous medication coverage }(7.8[1.6]) \\
\text { Reduced burden and increased satisfaction for families }(7.6[1.3]) \\
\text { Ability for the clinician to identify nonadherence immediately and intervene as soon as it is detected }(7.6[1.7]) \\
\text { Better symptom control for patient who might abuse substances and reduce or stop medication (7.6 [I.4]) } \\
\text { Improved patient and physician satisfaction }(7.4[1.3]) \\
\text { No or minimal concern about LAI being taken incorrectly or misused because staff are administering (reduced } \\
\text { risk of unintentional or deliberate overdose) }(7.2[1.3])\end{array}$ \\
\hline $\begin{array}{l}\text { High second } \\
\text { line }^{b}\end{array}$ & $\begin{array}{l}\text { Ability for the clinician to discriminate inadequate response due to lack of efficacy versus poor response due to } \\
\text { adherence problems (7.I [2.0]) } \\
\text { No need for patient to refill prescription for oral medication }(6.9[2.1]) \\
\text { No concern about patient losing medication }(6.9 \text { [1.7]) } \\
\text { Ensures regular contact between patient and treatment team (6.7 [2.0]) } \\
\text { More time to focus on nonmedication-related issues rather than adherence issues in clinical sessions }(6.7 \text { [1.9]) } \\
\text { Reduced stigma associated with having to take daily psychiatric medication }(6.7 \text { [1.8]) } \\
\text { Patients who travel do not need to carry medication with them (6.4 [2.0]) } \\
\text { Less variation in peak-to-trough antipsychotic blood level with lower risk of peak-level side effects }(6.3[1.8])\end{array}$ \\
\hline
\end{tabular}

Notes: ${ }^{2}$ Rating scale: 1 = not important at all, 2-3 = not very important, 4-6 = somewhat important, 7-8 = important, $9=$ extremely important; bold indicates an option rated 9 by $\geq 50 \%$ of the experts. 'High second-line options are those for which the upper value of the $\mathrm{Cl}$ is $\geq 6.5$, the boundary for first line. Abbreviation: LAl, long-acting injectable antipsychotic.

or bipolar disorder. All options, with the exception of LAIs being less expensive than oral medication, were considered to be important facilitators of LAI use. More than half of experts agreed that reducing the risk of relapse and hospitalization and improving patient outcomes were extremely important facilitators of LAI use (rated 9 by $\geq 50 \%$ of experts). A complete list of facilitators rated as first line and high second line is provided in Table 4.

\section{Discussion}

Findings from this survey on patient selection for LAIs generally align with research on risk factors for nonadherence and poor outcomes in people with severe mental disorders. ${ }^{23,34}$ Consistent with current APA guidelines in schizophrenia, ${ }^{16}$ experts considered LAI antipsychotics an appropriate option for individuals with known nonadherence or questionable adherence. Beyond nonadherence, experts positioned LAIs as an appropriate treatment for patients with more severe illness or limited social supports or for those at a particularly high risk of relapse.

There was more consensus on what constitutes the appropriate use of LAIs for schizophrenia/schizoaffective disorder than for bipolar disorder. This tendency likely reflects a general lack of published data and experience to inform evidence-based treatment decisions on LAI use in patients with bipolar disorder. Overall, recommendations were similar for patients with fairly recent disease onset ( $<2$ years) versus those diagnosed and receiving medication for $\geq 2$ years, suggesting that experts may support broader use of LAIs beyond the current APA guidance. ${ }^{17}$ Although experts rated a greater number of scenarios as usually appropriate for LAI use when patients have questionable adherence, a number of additional clinical scenarios were also considered usually appropriate in patients with assumed adherence. This finding suggests that experts may recommend LAIs as a strategy to prevent relapse due to factors other than adherence alone or that they consider using LAIs preemptively, assuming that nonadherence is likely in the future.

When experts ranked potential barriers to LAI prescribing by healthcare providers, no barriers were consistently rated as being most important. This may indicate that most barriers were seen as surmountable. Consensus was achieved on several high second-line factors related to other types of barriers such as fear of needles (patient-related barrier), LAIs not being adequately covered by insurance plans (systemrelated barrier), and the appropriate dosage not being clear (medication-related barrier). Write-in answers on the 3 most important barriers to LAI use in patients with schizophrenia/ schizoaffective or bipolar disorder were medication cost/ lack of insurance reimbursement, negative perceptions of and stigma associated with LAIs, and lack of knowledge and experience concerning how to use and dose LAIs. 
These recommendations are consistent with the observations in a previous systematic literature review, which additionally reported regional differences in LAI prescribing based on acceptance of community-based systems of care. ${ }^{35}$ The experts agreed on numerous factors that may facilitate LAI use, with more than half of the experts rating reduced risk of relapse/hospitalization and improved patient outcomes as being extremely important facilitators. This is consistent with meta-analytic findings from mirror image and cohort studies of LAIs versus oral antipsychotics ${ }^{13,14}$ as well as several RCTs in patients with recently diagnosed schizophrenia. ${ }^{10-12}$

Although the 2004 APA schizophrenia guidelines generally recommended LAIs for patients who prefer an LAI or for those who are nonadherent, ${ }^{16}$ newer guidelines recommend LAI SGAs as first-line treatment for schizophrenia and as maintenance treatment for bipolar disorder. ${ }^{16,18,36}$ Although disadvantages of LAIs include longer time to achieve steady state and less flexibility with dose adjustments, ${ }^{1}$ LAIs may also simplify the treatment regimen and reduce patient medication-taking burden. ${ }^{1,5,37}$ Advantages of LAIs beyond potentially improving adherence include being able to obtain an accurate assessment of dosing and regularity of treatment actually received, potentially strengthening the therapeutic alliance, ${ }^{4}$ and slower antipsychotic clearance, which may decrease the risk of clinical deterioration if a patient abruptly discontinues treatment. ${ }^{1,5,37}$

Although expert consensus guidelines in France have recommended early use of LAIs for patients with schizophrenia, ${ }^{16}$ European surveys show that clinicians still tend to reserve LAIs for patients later in the disease course. ${ }^{38-40}$ Results from this survey suggest that a shift may be occurring in the USA, with experts and high prescribers viewing LAIs as also being appropriate early in the course of schizophrenia. Earlier use of LAIs may potentially limit the progressive decline in functioning associated with disease recurrence. ${ }^{41-43}$ Two prospective randomized trials in firstepisode patients with schizophrenia found that frontal lobe white matter volume changes differed between patients receiving the LAI risperidone than in those receiving oral risperidone; ${ }^{42,43}$ in the first of these studies, greater white matter volume in the LAI group was associated with faster reaction times during cognitive performance testing. ${ }^{42}$ The expert consensus survey reported here also suggests that LAIs are usually appropriate for early-stage schizophrenia, when patients have a lot to gain (and to lose) psychosocially and functionally. Clinically, however, LAIs do not seem to be used preferentially in younger patients. For example, Barnes et al found no age or sex differences between patients who were prescribed LAIs and those prescribed oral antipsychotics in a UK study. ${ }^{27}$

There are a number of limitations to this survey, including low overall response rate and a sample size that was relatively small and insufficient to compare the responses of research experts versus high prescribers. Additionally, the duration of time needed to complete the survey may introduce the risk of inconsistent responses. Further, LAIs were considered as a group and individual differences between LAIs were not emphasized when seeking expert opinion. However, the completion rate for this survey was high overall, and methodological strengths included the blinded format (survey respondents were not provided information on funding source) and US national representation of experts. Moreover, the methodology has previously been used to provide guidance for treatment decisions in patients with schizophrenia ${ }^{44,45}$ and bipolar disorder. ${ }^{46}$

Results from this expert consensus suggest that more research is needed to better understand how LAIs should be positioned in the treatment armamentarium for patients with schizophrenia/schizoaffective or bipolar disorder, including how barriers to LAI use should be addressed and how facilitators of use may be best utilized. The rest of the survey results are presented in an accompanying paper. ${ }^{47}$

In conclusion, where clinical trial data are insufficient, the expert consensus survey method provides quantitative data that can be used to develop clinical recommendations based on expert opinion. ${ }^{31}$ In addition to providing recommendations on the use of LAIs in patients with schizophrenia/ schizoaffective and bipolar disorders, these survey findings may also help guide future research in this area.

\section{Acknowledgments}

This study was funded by Otsuka Pharmaceutical Development \& Commercialization, Inc. Editorial support for the preparation of this manuscript was provided by Sheri Arndt, PharmD, and Alan Klopp, PhD, of C4 MedSolutions, LLC (Yardley, PA, USA), a CHC Group company, with funding from Otsuka Pharmaceutical Development \& Commercialization, Inc., and H Lundbeck A/S.

\section{Disclosure}

$\mathrm{MS}, \mathrm{MB}, \mathrm{CUC}$, and $\mathrm{JMK}$ received consulting fees from Otsuka for their roles in the beta testing of the survey and data analysis for this study. MS has received research support from the National Institutes of Health (NIH), Centers for Disease Control and Prevention, Janssen, Merck, Pfizer, Reinberger Foundation, Reuter Foundation, Alkermes, Otsuka, and the 
Woodruff Foundation; has been a consultant for Bracket, Neurocrine, Otsuka, Pfizer, Prophase, Health Analytics, and Supernus; has received royalties from Johns Hopkins University Press, Lexicomp, Oxford University Press, Springer Press, and UpToDate; has participated in CME activities for the American Physician Institute, CMEology, and MCM Education; and was compensated by Otsuka for her work on the survey development and data analysis for this study. SNL was an employee of Otsuka Pharmaceutical Development \& Commercialization, Inc., at the time of the study. CUC has received grant or research support from the National Institute of Mental Health, the Patient Centered Outcomes Research Institute, The Bendheim Foundation, and Takeda; has served as a member of advisory boards/the Data Safety Monitoring Boards for Alkermes, IntraCellular Therapies, Lundbeck, Neurocrine, Otsuka, Pfizer, and Sunovion; and has served as a consultant to Alkermes, Allergan, the Gerson Lehrman Group, IntraCellular Therapies, Janssen/Johnson \& Johnson, LB Pharma, Lundbeck, Medscape, Otsuka, Pfizer, ProPhase, Sunovion, Supernus, and Takeda. He has presented expert testimony for Bristol-Myers Squibb, Janssen, and Otsuka and has received honorarium from Medscape and travel expenses from Janssen/Johnson \& Johnson, Lundbeck, Otsuka, Pfizer, Sunovion, and Takeda. JMK has received honoraria for lectures and/or consulting from Alkermes, Bristol-Myers Squibb, Boehringer Ingelheim, Eli Lilly, Forrest, Genentech, Intracellular Therapeutics, Janssen, Johnson \& Johnson, Lundbeck, Merck, Neurocrine, Novartis, Otsuka, Pfizer, Pierre Fabre, Proteus, Reviva, Roche, Sunovion, Takeda, and Teva and is a shareholder of MedAvante, LB Pharma, and The Vanguard Research Group. FD is an employee of Otsuka Pharmaceutical Development \& Commercialization. HF is an employee of Lundbeck. RR is a paid consultant for Otsuka and was compensated for her work on the survey and data analysis. MB has received grant or research support from NIH and Otsuka. The authors report no other conflicts of interest in this work.

\section{References}

1. Brissos S, Veguilla MR, Taylor D, Balanzá-Martinez V. The role of long-acting injectable antipsychotics in schizophrenia: a critical appraisal. Ther Adv Psychopharmacol. 2014;4(5):198-219.

2. Kaplan G, Casoy J, Zummo J. Impact of long-acting injectable antipsychotics on medication adherence and clinical, functional, and economic outcomes of schizophrenia. Patient Prefer Adherence. 2013; 7:1171-1180.

3. Offord S, Wong B, Mirski D, Baker RA, Lin J. Healthcare resource usage of schizophrenia patients initiating long-acting injectable antipsychotics vs oral. J Med Econ. 2013;16(2):231-239.

4. Correll CU, Citrome L, Haddad PM, et al. The use of long-acting injectable antipsychotics in schizophrenia: evaluating the evidence. J Clin Psychiatry. 2016;77(Suppl 3):1-24.
5. Gigante AD, Lafer B, Yatham LN. Long-acting injectable antipsychotics for the maintenance treatment of bipolar disorder. CNS Drugs. 2012; 26(5):403-420.

6. Nasrallah HA. The case for long-acting antipsychotic agents in the post-CATIE era. Acta Psychiatr Scand. 2007;115(4):260-267.

7. Olivares JM, Rodriguez-Morales A, Diels J, et al; e-STAR Spanish Study Group. Long-term outcomes in patients with schizophrenia treated with risperidone long-acting injection or oral antipsychotics in Spain: results from the electronic Schizophrenia Treatment Adherence Registry (e-STAR). Eur Psychiatry. 2009;24(5):287-296.

8. Haddad PM, Kishimoto T, Correll CU, Kane JM. Ambiguous findings concerning potential advantages of depot antipsychotics: in search of clinical relevance. Curr Opin Psychiatry. 2015;28(3):216-221.

9. Kishimoto T, Robenzadeh A, Leucht C, et al. Long-acting injectable vs oral antipsychotics for relapse prevention in schizophrenia: a metaanalysis of randomized trials. Schizophr Bull. 2014;40(1):192-213.

10. Alphs L, Mao L, Lynn Starr H, Benson C. A pragmatic analysis comparing once-monthly paliperidone palmitate versus daily oral antipsychotic treatment in patients with schizophrenia. Schizophr Res. 2016;170(2-3):259-264.

11. Schreiner A, Aadamsoo K, Altamura AC, et al. Paliperidone palmitate versus oral antipsychotics in recently diagnosed schizophrenia. Schizophr Res. 2015;169(1-3):393-399.

12. Subotnik KL, Casaus LR, Ventura J, et al. Long-acting injectable risperidone for relapse prevention and control of breakthrough symptoms after a recent first episode of schizophrenia. A randomized clinical trial. JAMA Psychiatry. 2015;72(8):822-829.

13. Kishimoto T, Nitta M, Borenstein M, Kane JM, Correll CU. Long-acting injectable versus oral antipsychotics in schizophrenia: a systematic review and meta-analysis of mirror-image studies. J Clin Psychiatry. 2013;74(10):957-965.

14. Kishimoto T, Hagi K, Nitta M, et al. Effectiveness of long-acting injectable vs oral antipsychotics in patients with schizophrenia: a metaanalysis of prospective and retrospective cohort studies. Schizophr Bull. 2017;44(3):603-619.

15. Kane JM, Kishimoto T, Correll CU. Assessing the comparative effectiveness of long-acting injectable vs. oral antipsychotic medications in the prevention of relapse provides a case study in comparative effectiveness research in psychiatry. J Clin Epidemiol. 2013; 66(8 Suppl):S37-S41.

16. Llorca PM, Abbar M, Courtet P, Guillaume S, Lancrenon S, Samalin L. Guidelines for the use and management of long-acting injectable antipsychotics in serious mental illness. BMC Psychiatry. 2013;13:340.

17. Lehman AF, Lieberman JA, Dixon LB, et al; American Psychiatric Association; Steering Committee on Practice Guidelines. Practice guideline for the treatment of patients with schizophrenia, second edition. Am J Psychiatry. 2004;161(2 Suppl):1-56.

18. Chou YH, Chu PC, Wu SW, et al. A systemic review and experts' consensus for long-acting injectable antipsychotics in bipolar disorder. Clin Psychopharmacol Neurosci. 2015;13(2):121-128.

19. Yatham LN, Kennedy SH, Parikh SV, et al. Canadian Network for Mood and Anxiety Treatments (CANMAT) and International Society for Bipolar Disorders (ISBD) collaborative update of CANMAT guidelines for the management of patients with bipolar disorder: update 2013. Bipolar Disord. 2013;15(1):1-44.

20. Kane JM, Kishimoto T, Correll CU. Non-adherence to medication in patients with psychotic disorders: epidemiology, contributing factors and management strategies. World Psychiatry. 2013;12(3):216-226.

21. Lacro JP, Dunn LB, Dolder CR, Leckband SG, Jeste DV. Prevalence of and risk factors for medication nonadherence in patients with schizophrenia: a comprehensive review of recent literature. J Clin Psychiatry. 2002;63(10):892-909.

22. Carbon M, Correll CU. Clinical predictors of therapeutic response to antipsychotics in schizophrenia. Dialogues Clin Neurosci. 2014; 16(4):505-524. 
23. Garcia S, Martinez-Cengotitabengoa M, Lopez-Zurbano S, et al. Adherence to antipsychotic medication in bipolar disorder and schizophrenic patients: a systematic review. J Clin Psychopharmacol. 2016; 36(4):355-371.

24. Patel MX, Haddad PM, Chaudhry IB, McLoughlin S, Husain N, David AS. Psychiatrists' use, knowledge and attitudes to first- and second-generation antipsychotic long-acting injections: comparisons over 5 years. J Psychopharmacol. 2010;24(10):1473-1482.

25. Byerly MJ, Thompson A, Carmody T, et al. Validity of electronically monitored medication adherence and conventional adherence measures in schizophrenia. Psychiatr Serv. 2007;58(6):844-847.

26. Stephenson JJ, Tunceli O, Gu T, et al. Adherence to oral secondgeneration antipsychotic medications in patients with schizophrenia and bipolar disorder: physicians' perceptions of adherence vs. pharmacy claims. Int J Clin Pract. 2012;66(6):565-573.

27. Barnes TR, Shingleton-Smith A, Paton C. Antipsychotic long-acting injections: prescribing practice in the UK. Br J Psychiatry Suppl. 2009; 52:S37-S42.

28. Rauch AS, Fleischhacker WW. Long-acting injectable formulations of new-generation antipsychotics: a review from a clinical perspective. CNS Drugs. 2013;27(8):637-652.

29. Weiden PJ, Roma RS, Velligan DI, Alphs L, DiChiara M, Davidson B. The challenge of offering long-acting antipsychotic therapies: a preliminary discourse analysis of psychiatrist recommendations for injectable therapy to patients with schizophrenia. J Clin Psychiatry. 2015; 76(6):684-690.

30. Sajatovic M, DiBiasi F, Legacy SN. Attitudes toward antipsychotic treatment among patients with bipolar disorders and their clinicians: a systematic review. Neuropsychiatr Dis Treat. 2017;13:2285-2296.

31. Kahn DA, Docherty JP, Carpenter D, Frances A. Consensus methods in practice guideline development: a review and description of a new method. Psychopharmacol Bull. 1997;33(4):631-639.

32. Brook RH, Chassin MR, Fink A, Solomon DH, Kosecoff J, Park RE. A method for the detailed assessment of the appropriateness of medical technologies. Int J Technol Assess Health Care. 1986;2(1):53-63.

33. Weiden PJ, Preskorn SH, Fahnestock PA, Carpenter D, Ross R, Docherty JP; Roadmap Survey. Translating the psychopharmacology of antipsychotics to individualized treatment for severe mental illness: a roadmap. J Clin Psychiatry. 2007;68(Suppl 7):1-48.

34. Leclerc E, Mansur RB, Brietzke E. Determinants of adherence to treatment in bipolar disorder: a comprehensive review. J Affect Disord. 2013; 149(1-3):247-252.
35. Parellada E, Bioque M. Barriers to the use of long-acting injectable antipsychotics in the management of schizophrenia. CNS Drugs. 2016; 30(8):689-701

36. Kane JM, Garcia-Ribera C. Clinical guideline recommendations for antipsychotic long-acting injections. Br J Psychiatry Suppl. 2009;52: S63-S67.

37. Jarema M, Wichniak A, Dudek D, Samochowiec J, Bieńkowski P, Rybakowski J. [Guidelines for the use of second-generation long-acting antipsychotics]. Psychiatr Pol. 2015;49(2):225-241. Polish [with English abstract].

38. Geerts P, Martinez G, Schreiner A. Attitudes towards the administration of long-acting antipsychotics: a survey of physicians and nurses. BMC Psychiatry. 2013;13:58.

39. Heres S, Hamann J, Kissling W, Leucht S. Attitudes of psychiatrists toward antipsychotic depot medication. J Clin Psychiatry. 2006;67(12): 1948-1953.

40. Jaeger M, Rossler W. Attitudes towards long-acting depot antipsychotics: a survey of patients, relatives and psychiatrists. Psychiatry Res. 2010; 175(1-2):58-62.

41. De Risio A, Lang AP. History and therapeutic rationale of long acting antipsychotics. Curr Clin Pharmacol. 2014;9(1):39-52.

42. Bartzokis G, Lu PH, Amar CP, et al. Long acting injection versus oral risperidone in first-episode schizophrenia: differential impact on white matter myelination trajectory. Schizophr Res. 2011;132(1):35-41.

43. Bartzokis G, Lu PH, Raven EP, et al. Impact on intracortical myelination trajectory of long acting injection versus oral risperidone in first-episode schizophrenia. Schizophr Res. 2012;140(1-3):122-128.

44. Kane JM, Leucht S, Carpenter D, Docherty JP; Expert Consensus Panel for Optimizing Pharmacologic Treatment of Psychotic Disorders. The expert consensus guideline series. Optimizing pharmacologic treatment of psychotic disorders. Introduction: methods, commentary, and summary. J Clin Psychiatry. 2003;64(Suppl 12):5-19.

45. McEvoy JP, Scheifler PL, Frances A. The expert consensus guidelines series: treatment of schizophrenia. J Clin Psychiatry. 1999;60 (Suppl 11):1-80.

46. Keck PE, Perlis RH, Otto MW, Carpenter D, Docherty JP, Ross R. The expert consensus guideline series: treatment of bipolar disorder 2004. Postgraduate Medicine Special Report. 2004:1-116.

47. Sajatovic M, Ross R, Legacy SN, et al. Initiating/maintaining longacting injectable antipsychotics in schizophrenia/schizoaffective or bipolar disorder-expert consensus survey part 2. Neuropsychiatr Dis Treat. In press 2018. 


\section{Supplementary materials}

How to prescribe LAls?

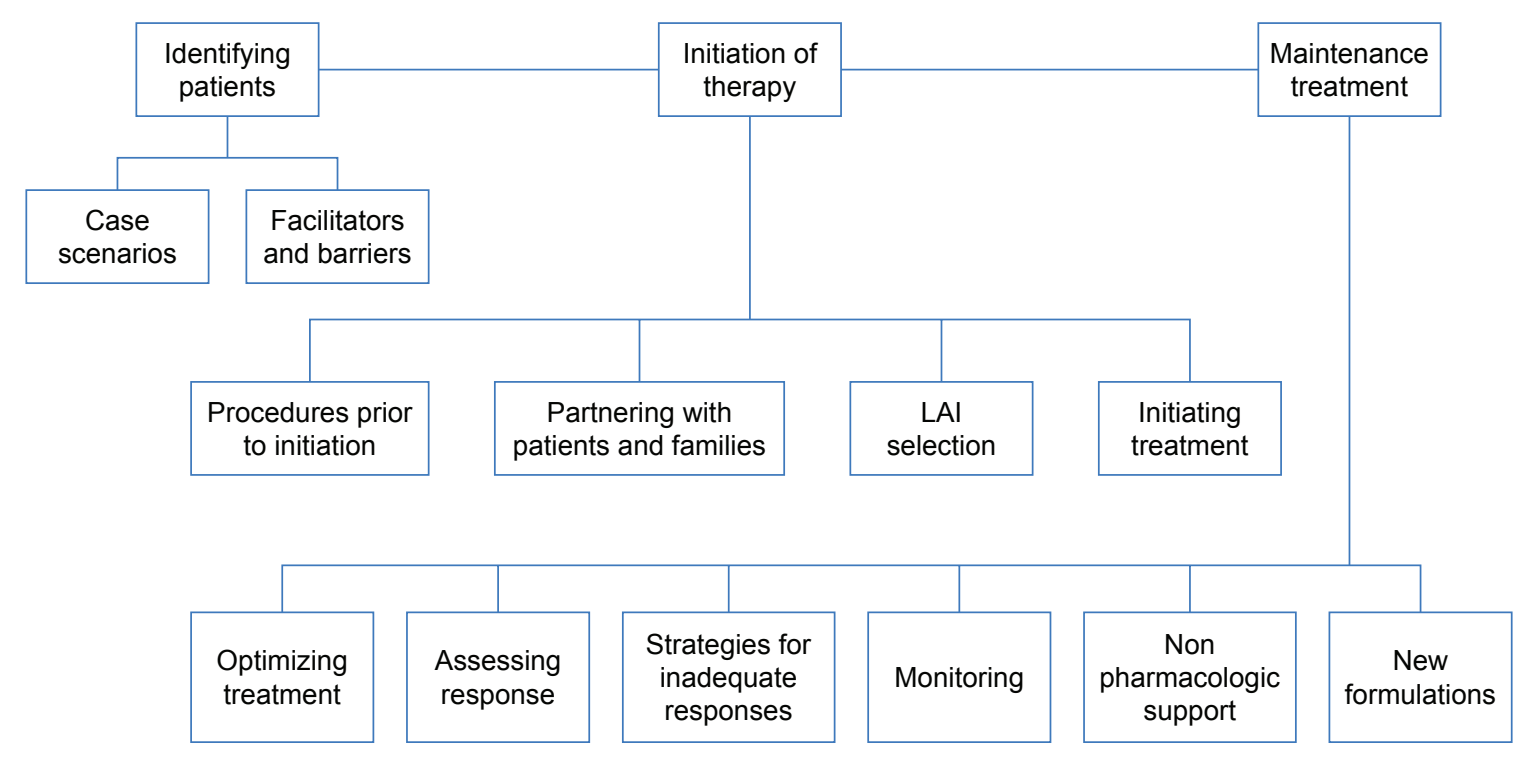

Figure SI Organization of survey.

Note: To simulate the treatment decision process, questions were organized into 3 main areas: identifying patients, initiation of therapy, and maintenance treatment. Abbreviation: LAl, long-acting injectable antipsychotic.

Table SI Survey respondents

Anissa Abi-Dargham, MD, Stony Brook University

Rimal Bera, MD, University of California, Irvine

Kelly Bliss, DNP, Mental Bliss, PLLC

William Carpenter, MD, Maryland Psychiatric Research Center, University of Maryland School of Medicine

Leslie Citrome, MD, MPH, New York Medical College

Christoph Correll, MD, The Zucker Hillside Hospital and Hofstra Northwell School of Medicine

Colin Depp, PhD, University of California, San Diego

Nassir Ghaemi, MD, Tufts Medical Center

Radhika Gollapudy, MD

Philip Harvey, PhD, University of Miami

Rona $\mathrm{Hu}, \mathrm{MD}$, Stanford University

Rakesh Jain, MD, MPH, Private Practice, Austin, TX, USA

Anita Kablinger, MD, CPI, Carilion Clinic, Virgnia Tech Carilion School of Medicine

John Kane, MD, The Zucker Hillside Hospital

Samuel Keith, MD, University of New Mexico

Paul Maguire, MD, Community Partners of Strafford County

Stephen Marder, MD, University of California, Los Angeles

Michael Measom, MD, New Roads/AD Psychotherapy/Volunteers of America

David Miklowitz, PhD, University of California, Los Angeles, Semel Institute

Frederick Mittleman, MD, CODAC-Health Recovery Wellness

Ricky Mofsen, DO, Evolution Research Group

Mary Moller, DNP, MSN, Pacific Lutheran University

Diana Perkins, MD, University of North Carolina

Stacey Rawls, MD, Private Practice, Rocky Mount, NC

Martha Sajatovic, MD, Case Western Reserve University School of Medicine

Stephen Saklad, PharmD, BCPP, The University of Texas at Austin, College of Pharmacy, Pharmacotherapy Division

Nina R. Schooler, PhD, SUNY Downstate Medical Center

Aimee Schwartz, MD, Terros Health

Asim Shah, MD, Baylor College of Medicine

Tracey Skale, MD, Greater Cincinnati Behavioral

Roger Sommi, PharmD, BCPP, University of Missouri-Kansas City Schools of Pharmacy and Medicine

Georgia Stevens, PhD, Director, P.A.L. Associates: Partners in Aging \& Long-Term Caregiving

Michael Thase, MD, University of Pennsylvania

Dawn Velligan, PhD, University of Texas Health Science Center at San Antonio 
Table S2 General summary of expert opinion on the top barriers to the use of LAls in the field

\begin{tabular}{|c|c|}
\hline Barriers to the use of LAls & $\begin{array}{l}\text { Experts who listed barrier as ranking in the } \\
\text { top } 3 \text { to limit the use of LAls, } n(N=3 I)\end{array}$ \\
\hline Cost/not on formulary/not reimbursed by insurance & 14 \\
\hline $\begin{array}{l}\text { Negative perception/prescriber bias/stigma associated with injections as coercive, } \\
\text { punitive, taking away patient autonomy/fear of impact on therapeutic alliance }\end{array}$ & 14 \\
\hline Lack of knowledge/experience with LAls and how to dose them & 11 \\
\hline $\begin{array}{l}\text { Lack of infrastructure and staff to use LAls/time constraints/concern about it } \\
\text { being more work to prescribe and provide LAls }\end{array}$ & 11 \\
\hline $\begin{array}{l}\text { Perceptions about the types of patients for whom LAls are appropriate (eg, only } \\
\text { patients who are nonadherent, who have had multiple relapses, who are seen as } \\
\text { the "worst of the worst," with schizophrenia but not bipolar disorder) }\end{array}$ & 9 \\
\hline Patient refusal/fear/dislike of injections & 8 \\
\hline $\begin{array}{l}\text { Concern about inability to adjust dosage/discontinue medication immediately as } \\
\text { needed, concern about persistence of potential side effects }\end{array}$ & 6 \\
\hline Problems presenting/explaining LAls to patients & 5 \\
\hline Availability of only a limited number of LAls with FDA indications & 3 \\
\hline Lack of family support & 3 \\
\hline Believing patients will reject LAls but not asking patients themselves & 2 \\
\hline Concern about patients not returning for injections & 2 \\
\hline Concern about pain at injection site & I \\
\hline Overestimation of patients' level of adherence & I \\
\hline Patient having to come into the office biweekly or monthly for injections & I \\
\hline Lack of awareness of the importance of adherence & I \\
\hline
\end{tabular}

Abbreviations: FDA, US Food and Drug Administration; LAI, long-acting injectable antipsychotic.

\section{Publish your work in this journal}

Neuropsychiatric Disease and Treatment is an international, peerreviewed journal of clinical therapeutics and pharmacology focusing on concise rapid reporting of clinical or pre-clinical studies on a range of neuropsychiatric and neurological disorders. This journal is indexed on PubMed Central, the 'PsycINFO' database and CAS, and is the official journal of The International Neuropsychiatric Association (INA). The manuscript management system is completely online and includes a very quick and fair peer-review system, which is all easy to use. Visit http://www.dovepress.com/testimonials.php to read real quotes from published authors. 